\title{
EDITORIAL
}

\section{Malignant pleural effusion: would the real cause please stand up?}

\author{
R.W. Light*, H. Hamm**
}

Pleural effusions in patients with malignant disease are not invariably due to metastatic spread to the pleura and thus, they are not always incurable. For example, about $5 \%$ of patients with effusions due to lung cancer have subsequently been found to be operable and curable [1]. It is, therefore, important to assess the potential curability in all cancer patients with cytologically negative effusions, since they may not only be free from pleural metastases but also from tumour spread elsewhere.

On the other hand, autopsy studies indicate that only about $55-60 \%$ of patients with proven pleural metastases develop pleural effusions. What are the mechanisms that cause the development of an effusion in one patient with malignant involvement of the pleura and what prevents it in another?

In this issue of the Journal, SAHN [2] suggests that neoplastic involvement of the lymphatic drainage system, either in the parietal pleura and/or in the mediastinum, is the primary mechanism by which pleural metastases cause pleural effusions. This leads to accumulation of the fluid which normally leaves the pleural space. These conclusions are based primarily on postmortem studies in which the presence of pleural effusions was correlated with the autopsy findings [3, 4]. If the lymphatic clearance is normal, excess fluid that enters the pleural space can usually be removed, since the maximum capacity of the lymphatics for fluid removal is up to 25 times the normal rate of fluid formation [5]. Therefore, unless the amount of pleural fluid being formed is very high, pleural fluid will accumulate only if there is also decreased lymphatic clearance. Indeed, it has been shown that the clearance of fluid from the pleural space is decreased in patients with malignant pleural effusions [6].

However, there are several observations that seem to be incompatible with the theory that lymphatic obstruction is solely responsible for the pleural fluid accumulation.

Firstly, malignant pleural effusions are exudates. If the pleural effusion developed solely as a consequence of lymphatic obstruction, one would anticipate that the fluid would be a transudate, since the fluid that normally enters the pleural space is a low-protein ultrafiltrate from the parietal side [7-9].

Secondly, the rate of pleural fluid formation, at least

*Pulmonary Disease Program, St Thomas Hospital, Nashville, Tennessee, USA. **Abt. Pneumologie, Medizinische Universitätsklinik, Freiburg, Germany.

Correspondence: R.W. Light, Pulmonary Disease Program, St Thomas Hospital, 4220 Harding Road, Nashville, Tennessee 37205, USA. in some patients, is much too high to be explained on the basis of lymphatic obstruction. If data in sheep can be extrapolated to humans, the normal rate of pleural fluid formation is about $0.01 \mathrm{~mL} \cdot \mathrm{kg}^{-1} \cdot \mathrm{h}^{-1}$ [10]. In a 60 $\mathrm{kg}$ individual, only about $15 \mathrm{~mL}$ of pleural fluid would accumulate during each $24 \mathrm{~h}$ with complete lymphatic obstruction. In the clinical arena, many patients with malignant pleural effusions have pleural fluid accumulation rates many times greater than this. After patients with malignant pleural effusions have chest tubes inserted and the hemithorax drained, it is common for the fluid egress to exceed $100 \mathrm{~mL} \cdot$ day $^{-1}$.

Thirdly, if the accumulation of pleural fluid was due solely to lymphatic obstruction, why are malignant cells found in more than $90 \%$ of effusions [12], and why are so many malignant effusions bloody? A possible explanation for the high rate of positive cytology is the invasion of the parietal pleura by the metastatic tumour as it obstructs the lacunae of the lymphatics. However, it has been shown that many patients have effusions only when their visceral pleura is involved $[3,11,12]$. The visceral involvement probably represents bloodborne metastases from the primary tumour and leads to secondary spread across the pleural space to the parietal side. However, given that severe visceral and parietal involvement is usually observed in malignant pleural effusions, why should this not be an important cause of pathological fluid formation in itself?

We believe (although we have no direct proof) that increased pleural fluid formation contributes significantly to the development of a malignant pleural effusion. There are several possible explanations for this. The presence of pleural metastases may increase the permeability of the capillaries in the visceral and/or parietal pleura. This would also explain why malignant effusions are exudates. Further, the presence of a primary tumour or metastases in the lung may increase the amount of interstitial fluid, which would then add to increased pleural fluid formation. Finally, the presence of mediastinal lymph node involvement might decrease lymphatic flow from the lung and lead to increased amounts of fluid entering the pleural space by traversing the visceral pleura.

We suggest that pleural fluid accumulates due to the combination of both increased pleural fluid formation and a decreased capacity of the lymphatics to remove fluid. Only the combination of these two mechanisms gives us an answer to some of the theoretical problems that we have with the one single hypothesis, and this formulation may also better explain why some patients with pleural metastases have malignant effusions while others do not. 


\section{References}

1. Decker DA, Dines DE, Payne WS, Bernatz PE, Pairolero PC. The significance of a cytologically negative pleural effusion in bronchogenic carcinoma. Chest 1978; 74: 640-642.

2. Sahn SA. Pleural diseases related to metastatic malignancies. Eur Respir J 1997; 10: 1907-1913.

3. Meyer PC. Metastatic carcinoma of the pleura. Thorax 1966; 21: 427-433.

4. Chernow B, Sahn SA. Carcinomatous involvement of the pleura: an analysis of 96 patients. Am J Med 1977; 63: 695-702.

5. Broaddus VC, Wiener-Kronish JP, Berthiaume Y, Staub NC. Removal of pleural liquid and protein by lymphatics in awake sheep. J Appl Physiol 1988; 64: 384-390.

6. Leckie WJH, Tothill P. Albumin turnover in pleural effusions. Clin Sci 1965; 29: 339-352.
7. Miserocchi G, Agostoni E. Contents of the pleural space. J Appl Physiol 1971; 30: 208-213.

8. Miserocchi G. Physiology and pathophysiology of pleural fluid turnover. Eur Respir J 1997; 10: 219225.

9. Kinasewitz GT. Transudative effusions. Eur Respir $J$ 1997; 10: 714-718

10. Broaddus VC, Araya M, Carlton DP, Bland RD. Developmental changes in pleural liquid protein concentration in sheep. Am Rev Respir Dis 1991; 143: 38-41.

11. Rodriguez-Panadero F, Borderas Naranjo F, Lopez Mejias J. Pleural metastatic tumours and effusions. Frequency and pathogenetic mechanisms in a post-mortem series. Eur Respir J 1989; 2: 366-369.

12. Canto A, Rivas J, Saumenench J, Morera R, Moya J. Points to consider when choosing a biopsy method in cases of pleurisy of unknown origin. Chest 1983; 84: 176-179. 